\title{
Treat your bug right
}

\author{
Shuping Vincent $\mathrm{Wu}^{1,2 *}$ and Hongxiang Hui ${ }^{2,3}$ \\ 1 VA Greater Los Angeles Healthcare System, Los Angeles, CA, USA \\ 2 Center for Excellence in Pancreatic Diseases, David Geffen School of Medicine at University of California Los Angeles, Los Angeles, CA, USA \\ ${ }^{3}$ Southern Medical University, Guangzhou, China \\ *Correspondence:vwu@ucla.edu
}

\section{A commentary on}

Microbial induction of immunity, inflammation, and cancer

by Greer, J. B., and O'Keefe, S. J. (2011).

Front. Physiol. 1:168. doi: 10.3389/

fphys.2010.00168

There is growing awareness of the importance of gut bacteria in human health by both researchers and the general public. The recent release of a human gut microbial gene catalog of more than a thousand bacterial species from a European cohort (Qin et al., 2010) exemplifies the rapid expansion of our knowledge of the other genome in humans - the gut bacterial genome. Highlighted in the review by Greer and O'Keefe (2011), the constitution of enteric microbiota is more diverse in rural African than European children (De Fillipo et al., 2010), underscoring the evolution and adaptation of the gut flora within the environment of the human host. Cellular and molecular evidence to support the role of the microbiota in inflammatory and other human diseases has been well documented (Table 1 of the Greer and O’Keefe, 2011).

Previous studies to delineate the interaction between pathogenic bacteria and the host mucosal immune system have identified several molecular targets, termed pattern recognition receptors (PRR), which include toll-like receptors (TLR), Nod-like receptors, and RNA helicase family members (Fukata and Abreu, 2009). Membrane-bound TLRs, in particular, have been extensively characterized to construct plausible mechanistic pathways by which pathogens elicit immune responses and compromise gut immunity leading to mucosal dysfunction, inflammatory bowel disease, and cancer.

The present review addresses gut bacterial-host interactions and their benefits, including the influence of maternal and postnatal adaptive nutrient metabolism, the lack of beneficial bacteria resulting from a Western diet, and hygienic practices. Interestingly, the authors cite butyrate as a specific example to demonstrate its beneficial role in several of these processes. Butyrate, a short-chain fatty acid (SCFA), has been shown to be involved in the regulation of energy consumption and immune function as well as cell growth and apoptosis in intestinal mucosa. Of note, many SCFAs, including butyrate, may act by signaling mechanisms involving a membrane-bound G-protein coupled receptor, GPR43, to modulate functions of endocrine (Maslowski et al., 2009) and enteric neuronal cells (Soret et al., 2010).

This review raises several salient points pertinent to microbial-induced physiologic and pathological responses. In particular, topics include (i) the effect of the Western diet and feeding behavior on food metabolism by gut bacteria resulting in increased disease risk; (ii) a plausible hygiene hypothesis based on well-recognized altered bacterial exposure and compromised gut immunity; and (iii) the potential beneficial role of butyrate in maintaining gut health and preventing GI diseases. Finally, the authors' suggestions to modify unfavorable dietary and hygienic behaviors through medical practice and public education are potential useful steps toward a harmonic coexistence of people with their gut bacteria.

\section{REFERENCES}

De Fillipo, C., Cavalieri, D., Di Paola, M., Ramazzotti, M., Poullet, J. B., Massart, S., Collini, S., Pieraccini, G., and Lionetti, P. (2010). Impact of diet in shaping gut microbiota revealed by a comparative study in children from Europe and rural Africa. Proc. Natl. Acad. Sci. U.S.A. 107, 14691-14696.

Fukata, M., and Abreu, M. T. (2009). Pathogen recognition receptors, cancer and inflammation in the gut. Curr. Opin. Pharmacol. 9, 680-687.

Greer, J. B., and O'Keefe, S. J. (2011). Microbial induction of immunity, inflammation, and cancer. Front. Physiol. 1:168. doi: 10.3389/fphys.2010.00168

Maslowski, K. M., Vieira, A. T., Ng, A., Kranich, J., Sierro, F., Yu, D., Schilter, H. C., Rolph, M. S., Mackay, F., Artis, D., Xavier, R. J., Teixeira, M. M., and Mackay, C. R. (2009). Regulation of inflammatory responses by gut microbiota and chemoattractant receptor GPR43. Nature 461, 1282-1286.

Qin, J., Li, R., Raes, J., Arumugam, M., Burgdorf, K.S. Manichanh, C., Nielsen, T., Pons, N., Levenez, F., Yamada, T., Mende, D.R., Li, J., Xu, J., Li, S., Li, D., Cao, J., Wang, B., Liang, H., Zheng, H., Xie, Y., Tap, J., Lepage, P., Bertalan, M., Batto, J.M., Hansen, T., Le Paslier, D., Linneberg, A., Nielsen, H.B., Pelletier, E., Renault, P., Sicheritz-Ponten, T., Turner, K., Zhu, H., Yu, C., Li, S., Jian, M., Zhou, Y., Li, Y., Zhang, X., Li, S., Qin, N., Yang, H., Wang, J., Brunak, S., Doré, J., Guarner, F., Kristiansen, K., Pedersen, O., Parkhill, J., Weissenbach, J.; MetaHIT Consortium, Bork, P., Ehrlich, S.D., and Wang, J.(2010). A human gut microbial gene catalogue established by metagenomic sequencing. Nature 464, 59-65.

Soret, R., Chevalier, J., De Coppet, P., Poupeau, G., Derkinderen, P., Segain, J. P., and Neunlist, M. (2010). Short-chain fatty acids regulate the enteric neurons and control gastrointestinal motility in rats. Gastroenterology 138, 1772-1782.

Received: 29 January 2011; accepted: 24 February 2011; published online: 07 March 2011.

Citation: Wu SV and Hui H (2011) Treat your bug right. Front. Physio. 2:9. doi: 10.3389/fphys.2011.00009

This article was submitted to Frontiers in Gastrointestinal Sciences, a specialty of Frontiers in Physiology.

Copyright (c) $2011 \mathrm{Wu}$ and Hui. This is an open-access article subject to an exclusive license agreement between the authors and Frontiers Media SA, which permits unrestricted use, distribution, and reproduction in any medium, provided the original authors and source are credited. 